\title{
Comparison of Fentanyl and Midazolam for the Sedation of Infants Under Mechanical Ventilation; A Randomized Clinical Trial
}

\author{
Bita Najafian', Bahareh Esmaeili², Mohammad Hossein Khosravi ${ }^{2,3^{*}}$ \\ ${ }^{1}$ Department of Pediatrics, Faculty of Medicine, Baqiyatallah University of Medical Sciences, Tehran, Iran \\ ${ }^{2}$ Student Research Committee (SRC), Baqiyatallah University of Medical Sciences, Tehran, Iran \\ ${ }^{3}$ International Otorhinolaryngology Research Association (IORA), Universal Scientific Education and Research \\ Network (USERN), Tehran, Iran
}

*Corresponding Author: Mohammad Hossein Khosravi, M.D., Student Research Committee (SRC), Baqiyatallah University of Medical Sciences, Mollasadra St., Vanaq Sq., Tehran, Iran. Tel: +989126441288, Email: dr.mhkhosravi@gmail.com

Received August 1, 2017; Accepted August 17, 2017, Online Published August 28, 2017

\begin{abstract}
Background: Neonatal respiratory distress syndrome (NRDS), a life-threatening pulmonary disorder, involves $1 \%$ of all deliveries worldwide. Shallow breathing causes restlessness in infants, which itself affects pulmonary function; thus, sedative medications are used to preserve better pulmonary function. There are different opinions about the benefits and superiority of these drugs.

Objective: The study purposed to assess and compare the effects of fentanyl and midazolam on the required time of mechanical ventilation in infants with respiratory distress syndrome (RDS).

Methods: In this randomized clinical trial, 60 infants with RDS were randomly allocated to 2 groups (30 infants each); the first group underwent sedation with midazolam $(0.1 \mathrm{mg} / \mathrm{kg})$, and the second group received $0.5 \mathrm{mcg} / \mathrm{kg}$ of fentanyl during ventilation. The duration of hospitalization, required time of ventilation, drug complications, feeding intolerance, as well as pneumothorax incidence and need for re-intubation were recorded and compared between the 2 groups.

Results: Eventually, 60 infants (45 male and 15 female) with a mean gestational age of $37.13 \pm 1.22$ weeks in the midazolam group and $36.73 \pm 1.50$ weeks in the fentanyl group underwent analysis $(P$ value $=0.449)$. Infants in the midazolam group had a mean length of stay of $11.96 \pm 3.41$ days, while mean length of stay was $10.36 \pm 3.57$ days for infants in the fentanyl group $(P$ value $=0.039)$. Mean duration of mechanical ventilation was $4.6 \pm 2.14$ days in the midazolam group and $4.06 \pm 2.04$ days in the fentanyl group ( $P$ value $=0.252$ ).

Conclusion: The findings suggest that midazolam is a more suitable medication for the sedation of infants under mechanical ventilation in comparison with fentanyl; however, its side effects, such as apnea, pneumonia, and seizure, should be considered.
\end{abstract}

Keywords: Midazolam, Fentanyl, Respiratory Distress Syndrome, Mechanical Ventilation

\section{Background}

Neonatal respiratory distress syndrome (NRDS), also known as hyaline membrane disease (HMD), is a lifethreatening pulmonary disorder and a medical emergency. It involves approximately $1 \%$ of all deliveries worldwide. ${ }^{1}$ Based on United States statistics, 60000 to 80000 infants are born with NRDS each year, of which 6000 to 12000 usually die. About $20 \%$ of these infants are affected by a chronic pulmonary disease called bronchopulmonary dysplasia (BPD). The main cause of this disease is a shortage or lack of surfactant, which results in decreased functional residual volume and an increased tendency of the lungs for atelectasis and collapse. ${ }^{1}$

The building block of respiratory distress syndrome (RDS) treatment is the prescription of surfactant therapy and respiratory support. ${ }^{2-4}$ There are a variety of methods for helping the respiration of infants with RDS, including mechanical ventilation. ${ }^{5,6}$ Shallow breathing results in restlessness and stress in infants, which affect pulmonary function; thus, sedative medications are used to preserve better pulmonary function. ${ }^{7}$

Fentanyl, an opioid drug, is used in injection form $(0.5$ $\mathrm{mcg} / \mathrm{kg}$ ) during mechanical ventilation to induce sedation. ${ }^{8}$ Benzodiazepines such as midazolam $(0.1 \mathrm{mg} / \mathrm{kg})$ are also

Copyright $(2017$ The Author(s). This is an open-access article distributed under the terms of the Creative Commons Attribution License (http:// creativecommons.org/licenses/by/4.0), which permits unrestricted use, distribution, and reproduction in any medium, provided the original work is properly cited. 
used to induce sedation and sleep by effecting GABA receptors. ${ }^{9}$ There are different opinions about the benefits and superiority of these drugs.

\section{Objective}

Because of the controversies in opinion, the present study aimed to assess and compare the effects of fentanyl and midazolam on the required time of mechanical ventilation in infants with RDS.

\section{Methods}

This randomized clinical trial was conducted between July 2016 and March 2017 at the neonatal intensive care unit (NICU) of Najmiyeh University Hospital, Tehran, Iran. Figure 1 shows a flowchart of the trial. Infants with a confirmed diagnosis of RDS based on chest radiography, respiratory rate, arterial blood gas (ABG), first and fifth minute Apgar scores, grunting, cyanosis, and physical examination by a single neonatologist were enrolled in the trial. Infants between 2.5 and $4 \mathrm{~kg}$ of weight who needed intubation and mechanical ventilation were included in the study. Patients with weights lower than $2.5 \mathrm{~kg}$ or greater than $4 \mathrm{~kg}$ as well as those with congenital heart disease, brain anomalies, or metabolic or chromosomal syndromes were excluded from the trial. Demographic as well as peri-natal information such as birthweight, gestational age, mother's disease during pregnancy, Apgar scores, and method of delivery were recorded in a pre-designed checklist.

After the study process was explained and informed consent forms were obtained from the parents, the patients were randomly allocated to two groups; the first group underwent sedation with midazolam $(0.1 \mathrm{mg} / \mathrm{kg})$, and the second group received $0.5 \mathrm{mcg} / \mathrm{kg}$ of fentanyl during ventilation. Duration of hospitalization, required time of ventilation, drug complications, feeding intolerance, pneumothorax incidence, and need for re-intubation were recorded and compared between the 2 groups.

Data analyses were performed using the Statistical Package for Social Sciences (SPSS) version 21 for Windows software (IBM Corp, Armonk, NY). Normal distributed variables (approved by 1-sample KolmogorovSmirnov test) were compared using independent sample $t$ test between the groups. The chi square test was used to compare categorical variables in the two groups. Mean and standard deviation (SD) were used to describe categorical variables.

\section{Results}

Eventually, 60 infants ( 45 male and 15 female) with a mean gestational age of $37.13 \pm 1.22$ weeks in the midazolam (30 infants) group and $36.73 \pm 1.50$ weeks in the fentanyl group (30 infants) underwent analysis $(P$ value $=0.449)$. Of all patients, $52(87 \%)$ infants were delivered by natural

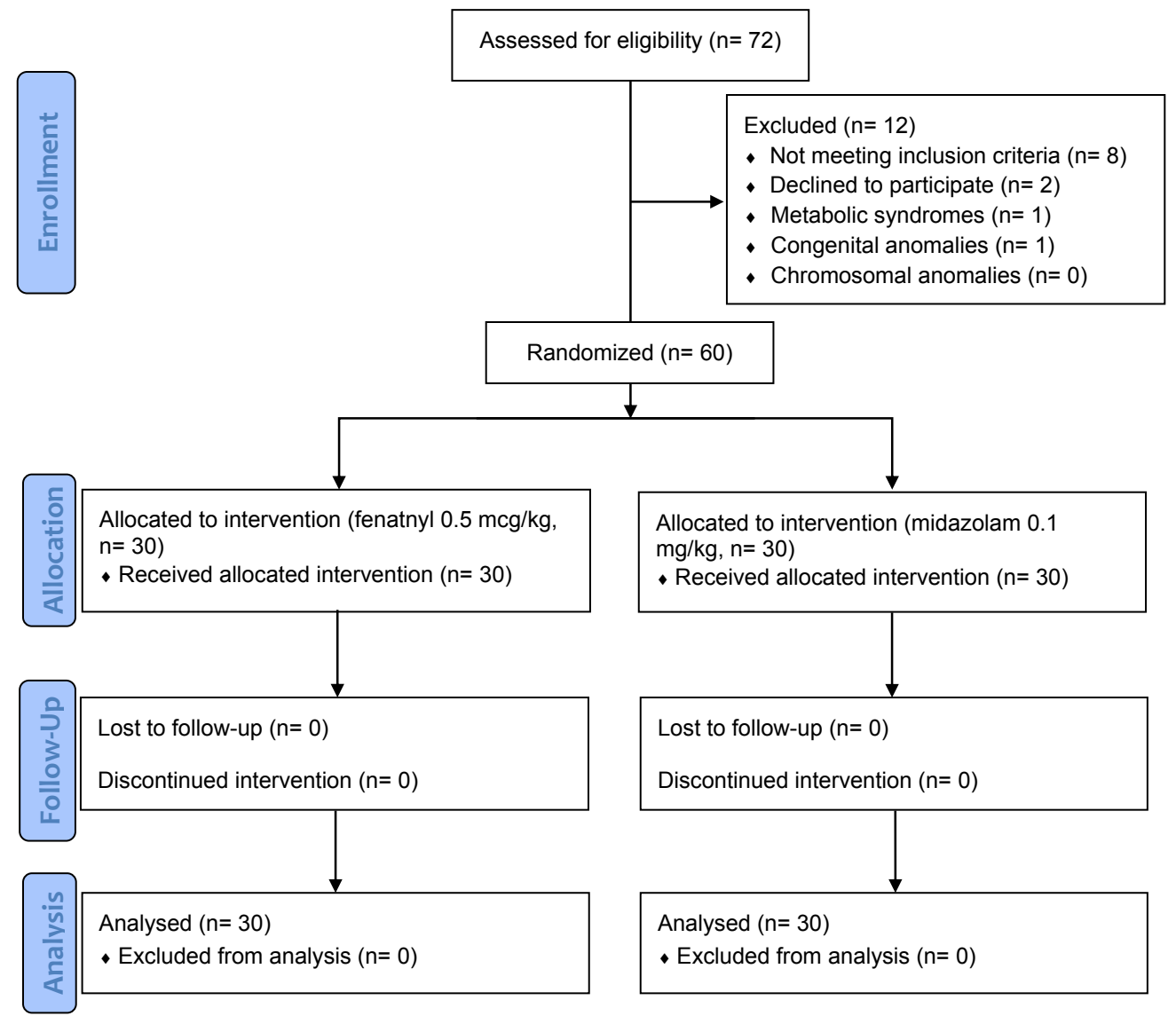

Figure 1. Study Flowchart. 
vaginal delivery (NVD) and 8 (13\%) patients were delivered by cesarean section. Table 1 shows pregnancyrelated complications in the study individuals. There were no cases of addiction, chorioamnionitis, or decollement. Mean birthweights were $2.94 \pm 0.39 \mathrm{~kg}$ and $2.85 \pm 0.50$ $\mathrm{kg}$ in the midazolam and fentanyl groups, respectively. During the trial, $52(86.7 \%)$ infants received surfactant therapy, $6(10 \%)$ received phenytoin, and 11 (18.3\%) received phenobarbital (Table 2 ). $\mathrm{N}$-acetylcysteine was not prescribed for any of the infants.

In total, patients were hospitalized for $11.16 \pm 3.56$ days in both groups. Infants in the midazolam group had a mean length of stay of $11.96 \pm 3.41$ days, while infants in the fentanyl group had a mean length of stay of $10.36 \pm 3.57$ days $(P$ value $=0.039)$. Mean duration of mechanical ventilation was $4.6 \pm 2.14$ days in the midazolam-group and $4.06 \pm 2.04$ days in fentanyl group $(P$ value $=0.252)$.

Table 3 summarizes the information on respiratory rate, heart rate, need for mechanical ventilation, oxygen dependency, mean arterial oxygen pressure, and mean arterial $\mathrm{CO} 2$ pressure in the study groups. Mean respiratory rate was $73.33 \pm 10.52$ per/minute before and $56.66 \pm 11.84 \mathrm{per} / \mathrm{minute}$ after intervention in all infants $(P$ value $=0.00)$. Mean respiratory rate was significantly decreased in each group after intervention; however, these means were not significantly different between the two groups after intervention $(P$ value $=0.313)$. Mean heart rate was $140.16 \pm 10.33$ per/minute before and $133.3 \pm 22.45$ per/minute after intervention in the study individuals $(P$ value $=0.011)$. Infants in the midazolam group had a significantly lower heart rate after intervention ( $P$ value $=0.001)$. Before intervention $38(63.3 \%)$ infants and after intervention $38(63.3 \%)$ infants needed mechanical ventilation $(P$ value $=0.001)$. Of all 60 patients, $45(75 \%)$ infants before and $44(73.3 \%)$ infants after intervention were oxygen-dependent $(P$ value $=0.768)$. There was no significant difference between the two groups in oxygen dependency after intervention. Mean arterial oxygen pressure was $55.43 \pm 8.79 \mathrm{~mm} \mathrm{Hg}$ before and $65.5 \pm 5.91$ $\mathrm{mm} \mathrm{Hg}$ after intervention in the study individuals $(P$ value $=0.321)$. There was no significant difference

Table 1. Pregnancy-Related Complications in Study Individuals

\begin{tabular}{llll}
\hline Complication & Midazolam $(\mathbf{n = 3 0})$ & Fentanyl $(\mathbf{n = 3 0})$ & $\boldsymbol{P}$ Value \\
\hline Gestational diabetes & 6 & 2 & 0.129 \\
Hypertension & 2 & 2 & $>0.05$ \\
PROM & 1 & 0 & 0.313 \\
Thick meconium & 2 & 0 & 0.150 \\
\hline
\end{tabular}

Table 2. Additional Medications Administered During Trial

\begin{tabular}{llll}
\hline Complication & Midazolam $(\mathbf{n = 3 0})$ & Fentanyl $(\mathbf{n = 3 0})$ & $\boldsymbol{P}$ Value \\
\hline Surfactant & 25 & 27 & 0.448 \\
Phenytoin & 5 & 1 & 0.085 \\
Phenobarbital & 7 & 4 & 0.317 \\
\hline
\end{tabular}

between the 2 groups in mean arterial oxygen pressure after intervention $(P$ value $=0.139)$. Mean arterial $\mathrm{CO} 2$ pressure was $38.33 \pm 5.71 \mathrm{~mm} \mathrm{Hg}$ before and $38.53 \pm 3.97$ $\mathrm{mm} \mathrm{Hg}$ after intervention $(P$ value $=0.702)$. This value was significantly lower in the fentanyl group infants after intervention $(P$ value $=0.001)$.

Pneumothorax was present only in 2 infants and pneumonia in 17 infants (Table 4). The most prevalent drug complication was drowsiness with 19 cases followed by apnea (13 infants), seizure (10 infants), respiratory depression (5 infants), irritability (5 cases), and hypotension (2 cases).

\section{Discussion}

In this study, it was found that the mean length of stay was significantly higher in the midazolam group infants

Table 3. Information on Respiratory Rate, Heart Rate, Need for Mechanical Ventilation, Oxygen Dependency, Mean Arterial Oxygen Pressure, and Mean Arterial CO2 Pressure in Study Groups

\begin{tabular}{|c|c|c|c|}
\hline Variable & $\begin{array}{l}\text { Midazolam } \\
(n=30)\end{array}$ & $\begin{array}{l}\text { Fentanyl } \\
(n=30)\end{array}$ & $P$ Value \\
\hline \multicolumn{4}{|c|}{ Respiratory rate } \\
\hline Before & $73.66 \pm 10.98$ & $73 \pm 10.22$ & 0.945 \\
\hline After & $53.33 \pm 12.99$ & $58 \pm 10.63$ & 0.313 \\
\hline \multicolumn{4}{|c|}{ Heart rate } \\
\hline Before & $138.83 \pm 1201$ & $141.5 \pm 8.32$ & 0.137 \\
\hline After & $125.8 \pm 24.47$ & $142 \pm 17.4$ & 0.001 \\
\hline \multicolumn{4}{|c|}{ Need for MV } \\
\hline Before & $24(80 \%)$ & $14(46.7 \%)$ & 0.001 \\
\hline After & $24(80 \%)$ & $13(43.3 \%)$ & 0.001 \\
\hline \multicolumn{4}{|c|}{ Oxygen dependency } \\
\hline Before & $27(90 \%)$ & $18(40 \%)$ & 0.007 \\
\hline After & $26(86.7 \%)$ & $18(60 \%)$ & 0.02 \\
\hline \multicolumn{4}{|c|}{ Mean Po2 } \\
\hline Before & $58.06 \pm 8.96$ & $52.8 \pm 7.91$ & 0.019 \\
\hline After & $66.63 \pm 5.49$ & $64.36 \pm 6.18$ & 0.139 \\
\hline \multicolumn{4}{|c|}{ Mean PCo2 } \\
\hline Before & $39.26 \pm 4.08$ & $37.4 \pm 6.92$ & 0.093 \\
\hline After & $40.5 \pm 4.15$ & $36.56 \pm 2.6$ & 0.001 \\
\hline
\end{tabular}

Table 4. Distribution of Treatment Complications Among Study Individuals

\begin{tabular}{lccc}
\hline Complication & $\begin{array}{c}\text { Midazolam } \\
(\mathbf{n}=\mathbf{3 0})\end{array}$ & $\begin{array}{c}\text { Fentanyl } \\
(\mathbf{n}=\mathbf{3 0})\end{array}$ & $\boldsymbol{P}$ Value \\
\hline Respiratory depression & 5 & 0 & 0.02 \\
Hypotension & 1 & 1 & 1 \\
Seizure & 7 & 3 & 0.166 \\
Irritability & 1 & 4 & 0.161 \\
Apnea & 10 & 0 & 0.028 \\
Drowsiness & 19 & 0 & 0.00 \\
PDA & 0 & 0 & 0.150 \\
Pneumonia & 9 & 8 & 0.774 \\
Pneumothorax & 2 & 0 & 0.150 \\
\hline
\end{tabular}


compared with the fentanyl group infants. No significant difference was observed between the 2 groups in mean duration of mechanical ventilation. Mean respiratory rate was significantly decreased after intervention in both groups, but the difference between the groups was not significant. In addition, mean heart rate was significantly decreased after intervention in the midazolam group; however, it was slightly increased in the fentanyl group infants. The number of infants who needed mechanical ventilation was not significantly changed after intervention; only one infant in the fentanyl group was off the ventilator. Mean arterial oxygen pressure was increased in study individuals after intervention, but this rate was not statistically significant. Mean arterial $\mathrm{CO} 2$ pressure was not significantly different after intervention; however, it was significantly lower in the fentanyl group infants.

Other similar studies have been conducted to assess the effects and complications of midazolam and fentanyl. The present study, however, was conducted with more detail by evaluating the abovementioned parameters in premature infants who were under mechanical ventilation.

Another similar study by Ancora et al evaluated the analgesic effect of fentanyl on infants under mechanical ventilation in comparison with a placebo group. The mean pain score was significantly lower for infants in the fentanyl group than those in the placebo group. Also, the authors reported that mean duration of ventilation was higher for infants in the fentanyl group. In their study, the mean length of stay was 10 days for the fentanyl group and 7 days for the placebo group. ${ }^{10}$

Zhu et al conducted a systematic review and metaanalysis in which they evaluated the effect of remifentanil on the duration of mechanical ventilation in comparison with other opioids such as fentanyl and morphine. They concluded that remifentanil reduces the duration of ventilation as well as the ICU length of stay (LOS). However, no significant differences were reported regarding hospital LOS, mortality, agitation, or costs. ${ }^{11}$

In their study, Welzing et al compared the need for mechanical ventilation of infants under 60 days of age in 2 groups, midazolam/fentanyl- and midazolam/ remifentanil-treated infants. They found that infants in the midazolam/remifentanil group had a lower duration of mechanical ventilation than those in the midazolam/ fentanyl group. ${ }^{12}$

Romantsik et al systematically reviewed studies in which clonidine was used for sedation and as an analgesia in neonates under mechanical ventilation. They reported that there is lack of efficient evidence; only one trial with 122 individuals was included which did not show any superiority in the clonidine prescription. ${ }^{13}$

\section{Conclusion}

In conclusion, the findings of the current study suggest that midazolam is a more suitable medication for the sedation of infants under mechanical ventilation in comparison

\section{Research Highlights}

\section{What Is Already Known?}

Shallow breathing results in restlessness and stress in infants which affect pulmonary function; thus, sedative medications are used to preserve better pulmonary function. Opioids such as fentanyl and benzodiazepines such as midazolam are used for this purpose; however, the superiority of either treatment is not clear.

\section{What This Study Adds?}

The current study found that midazolam $(0.1 \mathrm{mg} / \mathrm{kg})$ is a more suitable medication for the sedation of infants under mechanical ventilation in comparison with fentanyl 0.5 $\mathrm{mcg} / \mathrm{kg}$.

with fentanyl; however, its side effects, such as apnea, pneumonia, and seizure, should be considered.

Future studies with a larger sample volume are recommended. Furthermore, measurement of midazolam and fentanyl serum levels is suggested in further studies.

\section{Authors' Contributions}

$\mathrm{BN}$ designed the study and collected data. BS collected data and helped with manuscript drafting. MHK analyzed the data and drafted and critically revised the manuscript. All authors read and approved the final version of the manuscript.

\section{Conflict of Interest Disclosures}

None.

\section{Ethical Approval}

This study was approved by the Ethics Committee of the Islamic Azad University (Ref. No: IR.IAU.PS.REC.1394.14). This randomized clinical trial was registered at the Iranian Registry of Clinical Trial website (identifier: IRCT2017082417413N26; http://www.irct.ir).

\section{Acknowledgments}

The authors would like to thank all nurses and personnel of the NICU ward of Najmiyeh Hospital for their valuable cooperation.

\section{References}

1. Lynch RG. Surfactant and RDS in premature infants. FASEB J. 2004;18(13):1624.

2. Henderson-Smart DJ, Wilkinson A, Raynes-Greenow $\mathrm{CH}$. Mechanical ventilation for newborn infants with respiratory failure due to pulmonary disease. Cochrane Database Syst Rev. 2002(4):Cd002770. doi:10.1002/14651858.cd002770.

3. Stevens TP, Blennow M, Soll RF. Early surfactant administration with brief ventilation vs selective surfactant and continued mechanical ventilation for preterm infants with or at risk for RDS. Cochrane Database Syst Rev. 2002(2):Cd003063. doi:10.1002/14651858.cd003063.

4. Najafian B, Karimi-Sari H, Khosravi MH, Nikjoo N, Amin S, Shohrati M. Comparison of efficacy and safety of two available 
natural surfactants in Iran, Curosurf and Survanta in treatment of neonatal respiratory distress syndrome: a randomized clinical trial. Contemp Clin Trials Commun. 2016;3:55-59. doi: 10.1016/j.conctc.2016.04.003.

5. Goldsmith J, Karotkin E, Suresh G, Keszler M. Assisted Ventilation of the Neonate: Evidence-Based Approach to Newborn Respiratory Care. Elsevier Health Sciences; 2016.

6. Najafian B, Khosravi MH, Setayesh F, Shohrati M. comparing the effect of inhaler $\mathrm{N}$-acetyl cysteine and intravenous dexamethasone on respiratory distress syndrome in premature infants: a randomized clinical trial. Thrita. 2017;6(1):e46268. doi: $10.5812 /$ thrita.46268.

7. Shapiro PA, Fedoronko DA, Epstein LA, Mirasol EG, Desai CV. Psychiatric aspects of heart and lung disease in critical care. Crit Care Clin. 2008;24(4):921-47. doi:10.1016/j. ccc.2008.05.003.

8. Tobias JD. Sedation and analgesia in the pediatric intensive care unit. Pediatr Ann. 2005;34(8):636-645. doi: 10.3928/00904481-20050801-12.

9. Rosen DA, Rosen KR. Midazolam for sedation in the paediatric intensive care unit. Intensive Care Med. 1991;17 Suppl
1:S15-S19. doi:10.1007/BF01731149.

10. Ancora G, Lago P, Garetti E, et al. Efficacy and safety of continuous infusion of fentanyl for pain control in preterm newborns on mechanical ventilation. J Pediatr. 2013;163(3):645-51.e1. doi:10.1016/j.jpeds.2013.02.039.

11. Zhu Y, Wang Y, Du B, Xi X. Could remifentanil reduce duration of mechanical ventilation in comparison with other opioids for mechanically ventilated patients? A systematic review and meta-analysis. Crit Care. 2017;21(1):206. doi:10.1186/ s13054-017-1789-8.

12. Welzing L, Oberthuer A, Junghaenel S, Harnischmacher U, Stutzer H, Roth B. Remifentanil/midazolam versus fentanyl/ midazolam for analgesia and sedation of mechanically ventilated neonates and young infants: a randomized controlled trial. Intensive Care Med. 2012;38(6):1017-1024. doi:10.1007/ s00134-012-2532-1.

13. Romantsik O, Calevo MG, Norman E, Bruschettini M. Clonidine for sedation and analgesia for neonates receiving mechanical ventilation. Cochrane Database Syst Rev. 2017;5:Cd012468. doi:10.1002/14651858.CD012468.pub2. 